\title{
IDENTIDADE EM CRISE: UMA ABORDAGEM DE ALEXIS OU O TRATADO DO VÃO COMBATE, DE MARGUERITE YOURCENAR
}

\section{IDENTITY CRISIS: AN APPROACH OF ALEXIS OR THE TREATY OF THE COMBAT, OF MARGUERITE YOURCENAR}

Alex Rezende Heleno*

Resumo: O romance Alexis ou o tratado do vão combate, de Marguerite Yourcenar, consiste de uma longa carta, escrita por Alexis (personagem central), que é endereçada a Mônica, sua esposa. Na carta temos o relato de alguns momentos da vida do personagem que revela, principalmente, os conflitos em torno de uma identidade em crise diante da sociedade heterossexista de sua época e perante sua família, que têm por base a instituição do casamento. A análise do conflito relativo à constituição do sujeito e a aceitação de sua sexualidade têm ressonância nos estudos de Michel Foucault, Judith Butler, Susana Bornéo Funck etc, e pode nos confirmar a ideia de que a identidade de gênero ou a identidade sexual são produtos do discurso e da cultura e que o ser humano é um "sujeito em processo".

Palavras-chave: Identidade em crise. Gênero. Sujeito em processo.

Abstract: The novel Alexis ou o tratado do vão combate, by Marguerite Yourcenar, is a long letter, written by Alexis and directed to his wife Monique. In the letter, the main character tells us a few moments of his life and shows us his conflicts of identity living in a heterosexist society and a family who favour the institution of marriage. The analysis of the conflicts in the constitution of the subject and the acceptance of his sexuality will study next to the contribution of Michel Foucault, Judith Butler, Susana Borneo Funck, etc., and may confirm the idea that gender identity or sexual identity are products of discourse and culture, and that the human being is a "subject in process."

Keywords: Identity crises. Gender. Subject in process.

\footnotetext{
*Mestrando em Estudos Literários pela Universidade Federal de Viçosa, MG. Email: alexrezendeh@yahoo.com.br
} 
O romance Alexis ou o tratado do vão combate se constrói tendo por base o conflito gerado por uma crise de identidade vivenciada por Alexis, personagem central da obra de Marguerite Yourcenar. O texto é elaborado de forma que o leitor perceba e compreenda a (trans)formação do pensamento e das atitudes do personagem diante de todo um ambiente moral e religiosamente constituído, ou seja, um ambiente que vigia e controla as atitudes do indivíduo para que este siga o modelo predisposto e imposto como normativo pela sociedade. Como resultado, o personagem se aflige diante dos conflitos causados pelo choque entre os desejos pessoais (maior liberdade sexual e aceitação de sua homossexualidade) e as imposições morais da sociedade e da religião.

Quando Alexis se vê "diferente" do coletivo, temos a culminância de um pensar-se "individuo", ou seja, uma busca pela identidade que se mostrara perturbada por longos anos. Ele se solta das amarras de uma sociedade em que é valorizada a massificação do pensar, do agir e a crença na heterossexualidade como natural e normal (já que possibilita a "reprodução da espécie", como deseja a religião) para se conduzir por vias em que prevaleçam sua consciência e sua liberdade.

A noção de pecado que marca fortemente a vida do jovem é mostrada no romance como uma forma de controle e imposição, muitas vezes vazia de sentido, por exemplo, quando se trata das questões ligadas à exploração do corpo e aos desejos sexuais, que fazem parte da natureza humana, mas que são situações vistas como imorais. Esse controle faz surgir tabus linguísticos, impedindo que um diálogo sobre tais assuntos se tornem proibidos e sufocados. Conclui-se com Foucault que somos uma sociedade de vigilância, que impede a livre expressão do sujeito quando diz respeito à identidade de gênero, o que, em partes, pode explicar a não-aceitação de homossexuais, travestis etc., já que estes não se enquadram no "modelo heterossexual" fabricado:

Nossa sociedade não é de espetáculo, mas de vigilância: sob a superfície das imagens, investem-se os corpos em profundidade; atrás da grande abstração da troca, se processa o treinamento minucioso e concreto das forças úteis; os circuitos da comunicação são os suportes de uma acumulação e centralização do saber; o jogo dos sinais define os pontos de apoio do poder; a totalidade do indivíduo não é amputada, reprimida, alterada por nossa ordem social, mas o indivíduo é cuidadosamente fabricado, segundo uma tática das forças e dos corpos. (FOUCAULT, 2009, p.205).

A carta pode ser entendida, também, como uma resposta dada à sociedade já que esse pensar-se subjetivamente buscando compreender-se é uma forma de questionar as estruturas de poder que são alienantes e que fazem circular, por meio da mídia, ideologias de controle, de massificação e homogeneização de uma sociedade que é visivelmente heterogênea. É uma atitude que leva ao questionamento do que está sendo imposto ao indivíduo.

Nessa perspectiva, podemos entender o personagem como um "sujeito em processo"', ou seja, aquele que se vê numa

I ZOLIN, 2009, p. 233 
crise de identidade e decidi procurar uma solução para o conflito. É também aquele que será posto em processo no sentido da lei, da justiça, já que será questionado, cobrado e, certamente condenado pela "sociedade de vigilância". Contudo, a decisão de se aceitar prevalece no romance e o sujeito está disposto a enfrentar tais desafios, tornando-se um sujeito questionador das estruturas estabelecidas. A passagem retirada do prefácio do romance, escrito pela autora, nos orienta acerca do caminho a ser trilhado pelo personagem: "Alexis, abandonando sua mulher, apresenta como motivo de sua partida a procura de uma liberdade sexual mais completa e menos corrompida por mentiras, e é essa razão que, na verdade, permanece decisiva." (YOURCENAR, 1981, p. 10).

Percebemos pelo relato de Alexis que sua infância foi solitária e que, de acordo com a tradição da família, muitos assuntos eram proibidos. Além disso, uma vivência religiosa era frequente. Na passagem que se segue, o personagem fala desse silêncio, que é para ele uma falta grave, já que representa a impossibilidade de se confirmar em si próprio, de se conhecer:

Minha infância foi solitária e silenciosa, tornando-me tímido e, consequentemente, taciturno. Basta dizer que te conheço há quase três anos e só agora ouso falar-te de mim pela primeira vez! E ainda assim porque esta carta tornou-se inadiável. É terrível que o silêncio possa ser uma falta, a mais grave das minhas faltas. Mas eu a cometi. Antes de tê-la cometido para contigo, eu a cometi para comigo mesmo. (YOURCENAR, 1981, p. 27).
Esse silêncio, que também é imposto ao sujeito, torna-se perceptível quando o assunto está ligado às questões de gênero, de sexualidade. Há uma pobreza cultural para lidar com tais assuntos, vê-se que a sociedade ainda é patriarcal e heterossexista. Contudo, essa luta individual representa uma coletividade que é sufocada, reprimida e discriminada, mas que se mostra decidida a lutar contra a ignorância que é perpetuada por discursos pré-constituídos.

Confirmando o exposto, Butler considera haver um controle de corpos por meio do "sexo" por meio de uma prática regulatória:

\begin{abstract}
Nesse sentido, pois, o "sexo" não apenas funciona como uma norma, mas é parte de uma prática regulatória que produz os corpos que governa, isto é, toda força regulatória manifesta-se como uma espécie de poder produtivo - demarcar, fazer, circular, diferenciar - os corpos que ele controla. (BUTLER, 2001, p. 153-4).
\end{abstract}

O personagem se sente por um tempo confortável ao assumir uma identidade que não é sua, mas que é imposta por aqueles que o cercam: "Sentia-me satisfeito por viver segundo o ideal de moralidade passiva, um tanto tíbia, exaltado por todos à minha volta." (YOURCENAR, 1981, p. 50). Esse conforto inicial se tornará um conflito no momento em que essa "identidade outra" não estiver mais de acordo com os desejos corporais e sexuais do personagem.

Percebemos com Nolasco que, além da família, a escola - que incorpora as demandas comportamentais da sociedade sexista faz que a criança cresça na dúvida sobre os 
comportamentos: "No processo de socialização de um menino, surgem dúvidas que jamais se extinguem acerca do seu comportamento sexual, produzidas pela família e escola. Por meio dessa dúvida se estabelece o que é esperado de um menino: virilidade, agressividade e determinação." (NOLASCO, 1995, p. 18). Esses são fatores problemáticos em relação ao processo por que passa o sujeito. Isso pode ser visto como o motivo de se perpetuar práticas machistas e homofóbicas, que não aceitam comportamentos afeminados para o homem ou masculinizados para a mulher.

Essa prática regulatória faz prevalecer o ideal de uma sociedade heterossexual como norma. Utilizando-se da fala do personagem, pode-se dizer que: "A vida é algo mais que a poesia e é algo mais que a fisiologia, e até mesmo mais que a moral em que por tanto tempo acreditei." (YOURCENAR, 1981, p. 31-2). Não é a fisiologia do corpo ou a moral social e religiosa que devem ditar as normas sexuais e comportamentais. É a partir desses apontamentos que haverá a possibilidade de questionar a oposição binária homem/mulher e todo o discurso ultrapassado que caracteriza cada uma dessas esferas.

Essa oposição relacionada ao sexo pode ser entendida como o motivo causador da crise de identidade vivida pelo personagem. Quando ele nos diz que: "Não nos apaixonamos por aquelas a quem respeitamos, nem mesmo por aquelas a quem amamos. E, acima de tudo, não nos apaixonamos pelos nossos iguais. E não era certamente das mulheres que eu me sentia diferente." (YOURCENAR, 1981, p. 37), vemos que ao se identificar com as mulheres o personagem se vê cruzando um limite proibido pela moral e pela sociedade de controle que não aceita a "inversão dos papéis sociais".
Não se ver diferente das mulheres mostra que o binarismo "homem/mulher, macho/ fêmea, azul/rosa" não é uma fundamentação tranquila e que deve ser repensada e questionada em termos de um pensamento que respeite a diversidade.

Esse "sujeito em curso" se vê confrontado com limites que cabe a ele atravessar. O personagem do romance, Alexis, atravessa esse limite imposto ao gênero e ao sexo pela sociedade, como se percebe no excerto: "Repetia-me que a vida seria eternamente aquela parede cinzenta, aquelas vozes distantes e aquele mal-estar perturbador proveniente de não sei que angústia oculta." (YOURCENAR, 1981, p. 46). A angústia vivida pelo personagem é a mesma vivida por aqueles que saem dos limites heterossexistas, ou seja, homossexuais, travestis, lésbicas, transexuais etc.

A noção de pecado veiculada pela religião, e que pesa fortemente sobre o indivíduo, serve mais uma vez para pôr em crise uma identidade que está se processando: "A princípio, acreditei que se tratava apenas de evitar as ocasiões do pecado; logo percebi que nossas ações têm apenas o valor de sintomas; é nossa natureza que seria necessário mudar." (YOURCENAR, 1981, p. 74). Para estar em acordo com as normas comportamentais, o personagem acredita ser necessário mudar sua natureza. A angústia será o resultado desse choque entre desejos pessoais e os desejos do outro (heterossexual). Esse fato é comum em nossa sociedade que impõe ao sujeito práticas heteronormativas.

O espelho se torna emblemático no romance, pois é ele quem mostra a verdadeira identidade do personagem: "Odiava aquele espelho por infligir-me minha própria presença." (YOURCENAR, 1981, p. 75). Uma 
identidade que não é aceita pela sociedade e nem pelo personagem, que não se viu ainda como agente de sua própria escolha. O espelho representa "frente e verso" que não se sobrepõe, sendo, portanto, o símbolo para essa crise que se instala.

O conflito se agrava quando o personagem vê na instituição do casamento ${ }^{2}$ uma saída possível para seu conflito. Suas ideias religiosas e o peso do pecado o compeliram a esse fim. O casamento seria uma forma de agradar a família e a sociedade que estão em vigilância, mas o caminho tomado se torna um agravante para a situação do personagem.

O suicídio é visto pelo personagem como uma possibilidade de fuga, mas não chega a se efetivar: "Posso dizer-te que amava a vida. E foi em nome da vida, isto é, do meu futuro, que me esforcei por reconquistar-me a mim mesmo. [...] Passei pela obsessão do suicídio, como passei por outras ainda mais abomináveis." (YOURCENAR, 1981, p. 78). Essa crise de identidade pode, portanto, ter consequências fatais para aqueles que não conseguem chegar a uma compreensão e a uma aceitação de si próprios, como sujeitos de escolha.

Contudo, é a percepção de sua diferença em relação às demais pessoas que leva o personagem a negociar sua posição dentro da sociedade. De acordo com Giust-Desprairies (2005): "A identidade se inscreve no tempo, nos espaços e situações. Ela é um confronto e uma negociação renovados entre realidade e ideal, cujos resultados se fazem ver em termos de escolha, de investimento, de projetos ou de renúncias." (GIUST-DESPRAIRIES p. 202). O personagem renuncia, portanto, às

2 YOURCENAR, 1981, p. 75 máscaras que havia colocado para se conformar as cobranças da sociedade:

Prefiro o erro (se é erro) à negação de si mesmo que é o limite da demência. A vida me fez aquilo que sou, isto é, prisioneiro (se assim se quer) de instintos que não escolhi, mas aos quais me resigno e me entrego. À falta da felicidade, essa aceitação, assim espero, me proporcionará a paz. (YOURCENAR, 1981, p. 123).

A identidade procede, por conseguinte, de uma tensão conflitante entre as lógicas sociais e as necessidades do sujeito. Pode ser vista como uma forma de estabelecer ajustamentos num determinado tempo e contexto. ${ }^{3}$

O romance finaliza mostrando a aceitação, com ressalvas, do personagem acerca de sua identidade sexual. Aceita-se, mas sabe que os conflitos ainda persistiram por causa da visão restrita da sociedade heteronormativa:

Não tendo podido viver segundo os preceitos da moral estabelecida, procuro, pelo menos, estar de acordo com a minha própria. No momento em que decidimos renegar todos os princípios, é conveniente que conservemos, no mínimo, os escrúpulos. [...] Peço-te humildemente, o mais humildemente possível, perdão, não por te deixar, mas por ter ficado por tanto tempo. (YOURCENAR, 1981, p. 123/124). 
No prefácio ${ }^{4}$ da segunda edição do romance, publicado 40 anos depois da primeira edição que apareceu em 1929, Yourcenar nos diz que não fez alterações na obra tendo em vista que os conflitos vividos por Alexis não cessaram de existir e que o tema do romance é, ainda, atual. Isso nos mostra o quanto a problemática de gênero ainda é pouco disseminada e vista como subversiva em nossa sociedade. Mostra também como nossa sociedade tem repulsa pela variedade identitária. O discurso em torno das realidades sensuais ainda é preconceituoso, discriminatório e cercado de proibições.

De acordo com Susana Bornéo Funk ${ }^{5}$ (1992), a identidade, como a de gênero e a sexual são produtos da cultura e do discurso que ofuscam a diversidade humana ao impor categorias uniformizantes. Cabe a nós, estudiosos, pesquisadores e todos aqueles que buscam tornar visível variedade de identidade de gênero e sexo, lutar pela divulgação de tais estudos.

Categorias definidas e regulamentares acerca de identidade de gênero e sexo devem ser discutidas abertamente como uma forma de respeito à diversidade e ao próprio indivíduo, que em muitos casos se vê obrigado a se enquadrar em determinados padrões convencionados e aceitos pela sociedade. Esse choque entre indivíduo e sociedade, essa crise de identidade pode se tornar um grave problema quando coloca em risco a vida do indivíduo. E prezar pela vida, pela aceitação de si, pela variedade cultural e sexual é uma grande contribuição advinda dos estudos de gênero.

\section{REFERÊNCIAS}

BUTLER, J. Corpos que pesam: sobre os limites discursivos do "sexo". In: LOURO, Guacira Lopes (Org.). O corpo educado: pedagogias da sexualidade. 2. ed. Belo Horizonte: Autêntica, 2001, p. 153-172.

FOUCAULT, M. O panoptismo. In:

Vigiar e punir: o nascimento da prisão. Tradução de Raquel Ramalhete. 37.ed. Petrópolis, RJ: Vozes, 2009, p. 186- 214.

FUNK, S. B. O que é uma mulher? In: Cerrados: revista/ do Programa de Pós-Graduação em Literatura. Brasília, DF: UNB, v. 1, n. 1, 1992, p. 65-74.

GIUST-DESPRAIRIES, F. A identidade como processo, entre ligação e desprendimento". In: ZUGUEIB NETO, Jamil (Org.). Identidades e crises sociais na contemporaneidade. Curitiba: Ed. UFPR, 2005, p. 199-213.

NOLASCO, S. A desconstrução do masculino: uma contribuição crítica à análise de gênero. In: NOOLASCO, S. (Org.). A desconstrução do masculino. Rio de Janeiro: Rocco, (Gênero plural), 1995, p. 15-29.

YOURCENAR, M. Alexis ou o tratado do vão combate. Tradução de Martha Calderaro, Rio de Janeiro: Nova Fronteira, 1981.

ZOLIN, L. O. Crítica Feminista. In: BONNICI, T.; ZOLIN, L. O. Teoria literária: abordagens históricas e tendências contemporâneas. 3.ed. Maringá: EDUEM, 2010.

Recebido para publicação em 31 maio 2013. Aceito para publicação em 20 dez. 2013.

4 YOURCENAR, 1981, p. 06

5 FUNK, 1992, p. 67 